\title{
Comparison of 3D Synthetic Aperture Imaging and Explososcan using Phantom Measurements
}

\author{
Rasmussen, Morten Fischer; Férin, Guillaume ; Dufait, Rémi ; Jensen, Jørgen Arendt
}

Published in:

Proceedings of IEEE International Ultrasonics Symposium 2012

Publication date:

2012

Document Version

Early version, also known as pre-print

Link back to DTU Orbit

Citation (APA):

Rasmussen, M. F., Férin, G., Dufait, R., \& Jensen, J. A. (2012). Comparison of 3D Synthetic Aperture Imaging and Explososcan using Phantom Measurements. In Proceedings of IEEE International Ultrasonics Symposium 2012 IEEE.

\section{General rights}

Copyright and moral rights for the publications made accessible in the public portal are retained by the authors and/or other copyright owners and it is a condition of accessing publications that users recognise and abide by the legal requirements associated with these rights.

- Users may download and print one copy of any publication from the public portal for the purpose of private study or research.

- You may not further distribute the material or use it for any profit-making activity or commercial gain

- You may freely distribute the URL identifying the publication in the public portal

If you believe that this document breaches copyright please contact us providing details, and we will remove access to the work immediately and investigate your claim 
Paper presented at the IEEE International Ultrasonics Symposium, Dresden, Germany, 2012:

\section{Comparison of 3D Synthetic Aperture Imaging and Explososcan using Phantom Measurements}

Morten Fischer Rasmussen*, Guillaume Férin ${ }^{\dagger}$, Rémi Dufait ${ }^{\dagger}$ and Jørgen Arendt Jensen*

* Center for Fast Ultrasound Imaging,

Biomedical Engineering group, Department of Electrical Engineering, Bldg. 349,

Technical University of Denmark, 2800 Kgs. Lyngby, Denmark.

† Vermon S.A., Avenue du Génerál Renault, 37000 Tours, France.

To be published in Proceedings of IEEE International Ultrasonics Symposium, Dresden, Germany, 2012. 


\title{
Comparison of 3D Synthetic Aperture Imaging and Explososcan using Phantom Measurements
}

\author{
Morten Fischer Rasmussen*, Guillaume Férin ${ }^{\dagger}$, Rémi Dufait ${ }^{\dagger}$ and Jørgen Arendt Jensen* \\ ${ }^{*}$ Center for Fast Ultrasound Imaging, Dept. of Elec. Eng., \\ Technical University of Denmark, 2800 Kgs. Lyngby, Denmark. \\ †Vermon S.A., Avenue du Général Renault, 37000 Tours, France.
}

\begin{abstract}
In this paper, initial 3D ultrasound measurements from a 1024 channel system are presented. Measurements of 3D Synthetic aperture imaging (SAI) and Explososcan are presented and compared. Explososcan is the 'gold standard' for real-time 3D medical ultrasound imaging. SAI is compared to Explososcan by using tissue and wire phantom measurements. The measurements are carried out using a 1024 element $2 \mathrm{D}$ transducer and the 1024 channel experimental ultrasound scanner SARUS. To make a fair comparison, the two imaging techniques use the same number of active channels, the same number of emissions per frame, and they emit the same amount of energy per frame. The measurements were performed with parameters similar to standard cardiac imaging, with 256 emissions to image a volume spanning $90^{\circ} \times 90^{\circ}$ and $150 \mathrm{~mm}$ in depth. This results in a frame rate of $20 \mathrm{~Hz}$. The number of active channels is set to 316 from the design of Explososcan. From wire phantom measurements the point spread functions of both techniques were measured. At $40 \mathrm{~mm}$ depth Explososcan achieves a main lobe width (FWHM) of $2.5 \mathrm{~mm}$ while SAI's FWHM is $2.2 \mathrm{~mm}$. At $80 \mathrm{~mm}$ the FWHM is $5.2 \mathrm{~mm}$ for Explososcan and $3.4 \mathrm{~mm}$ for SAI, which is a difference of $35 \%$. Another metric used on the PSF is the cystic resolution, which expresses the ability to detect anechoic cysts in a uniform scattering media. SAI improved the cystic resolution, $R_{20 \mathrm{~dB}}$, at $40 \mathrm{~mm}$ depth from $4.5 \mathrm{~mm}$ to $1.7 \mathrm{~mm}$ and at $80 \mathrm{~mm}$ from $8.2 \mathrm{~mm}$ to $2.8 \mathrm{~mm}$, compared to Explososcan. The speckle pattern looked better for SAI compared to Explososcan's spatial shift variant speckle pattern.
\end{abstract}

\section{INTRODUCTION}

Ultrasound imaging has since the 1950s improved from advancements made in integrated electronics, computing power and transducer technology. This have led to an increase in both detail and dynamic resolution and has enabled advanced visualisations like color flow map and vector flow estimation. Although these technology advancements has led to high quality 2D imaging, a real-time 3D imaging system has not yet been implemented with a quality on par with $2 \mathrm{D}$ imaging.

Two major obstacles has delayed the implementation of realtime 3D imaging systems: the large amount of active channels needed to scan the volume with a 2D array transducer and the low frame rate achievable when scanning a full volume.

Explososcan is the gold standard of real-time 3D ultrasound imaging, developed by Smith, von Ramm and colleagues in the 1980s [1], [2]. It is a parallel beamforming technique which addresses the frame rate problem by beamforming multiple lines per emission. A broad transmit beam is emitted and multiple receive beams are focused in parallel during receive. This leads to a lower resolution and the amplitude of the outer receive beams are lower than the center ones.

The paper therefore investigates whether 3D synthetic aperture imaging (SAI) can improve resolution, contrast and remove the beam modulation artifact. Several versions of SAI exist. In this paper, SAI refers to synthetic transmit focusing (STF) where a transmit aperture is synthesized. Using STF the entire volume can be focused at all depths in transmit, in the same way as all depths can be in focus by using dynamic focus in receive.

Earlier work by the authors investigated the performance of 3D SAI and Explososcan using simulations [3]. In this paper, the imaging quality of SAI and Explososcan is investigated and compared using phantom measurements.

\section{Methods}

There are many degrees of freedom in the design of both Explososcan and SAI. Some constraints on the design process therefore have to be enforced. Both techniques are restricted to use only a fixed amount of active channels. The number of active channels and number of emissions used per imaged volume is determined by the design of Explososcan and then enforced on the design of synthetic aperture imaging. The design choices made during the implementation of the two techniques compared are described in this section.

\section{A. Explososcan}

The Explososcan system is designed with cardiac imaging in mind, which demands a wide scan area and a deep scan depth. A scan area of $90^{\circ} \times 90^{\circ}$ and a scan depth of $15 \mathrm{~cm}$ are chosen to be usable for cardiac imaging.

To limit the degrees of freedom in the design process of the imaging system, the number of beamformers is chosen to be 16 , beamforming $4 \times 4$ lines per emission. This gives a frame rate increase of 16 times compared to classic phased array imaging and is a standard choice in commercial systems. The imaged volume is scanned in 16 emissions per dimension, resulting in 256 emissions and 64x64 lines being beamformed in total. When scanning down to $15 \mathrm{~cm}$ a pulse repetition frequency, $f_{p r f}$, of $5 \mathrm{kHz}$ can be used, which leads to a frame rate of $20 \mathrm{~Hz}$. Since 16 emissions are used to scan $90^{\circ}$ per dimension, each transmit beam must have a main lobe width of $2 \alpha=90^{\circ} / 16=5.6^{\circ}$. The beamwidth at the focal point is found as:

$$
\mathrm{FWHM}=2 r \tan \alpha
$$




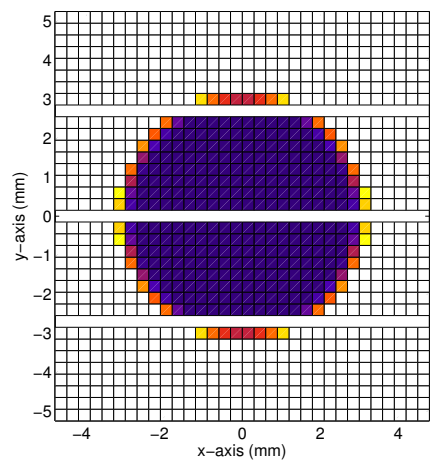

(a) TX aperture with apodization.

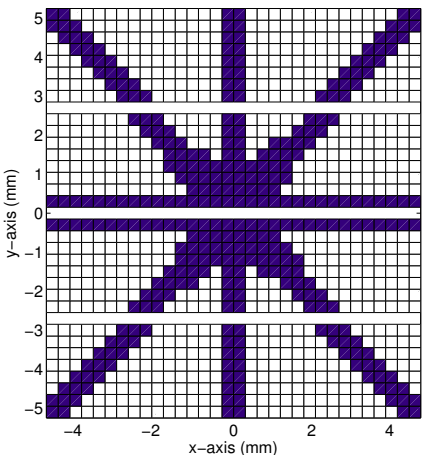

(b) RX aperture with apodization.
Fig. 1. The layout and apodization of Explososcan's transmit and receive aperture.

where $r$ is the distance from the aperture to the focal point and FWHM is the full width at half max. Eq. (1) comes from solving for the opposite side in the triangle made of the three points: the center of the transducer, the focal point and the point at the same depth as the focal point but offset by half the beamwidth (FWHM/2) to the side. The width of an aperture that has the FWHM from (1) is approximately:

$$
w=\frac{r \lambda}{\mathrm{FWHM}}=\frac{\lambda}{2 \tan \alpha},
$$

where $\lambda$ is the wavelength of the emitted wave and $w$ is the aperture width ${ }^{1}$. Inserting the values for $\lambda$ and $\alpha$ in (2) gives an aperture width of $5.22 \mathrm{~mm}$, or approximately 20 transducer elements. A circle with a diameter of 20 has an area of 314 , but because symmetry is desired, 316 elements are used in the transmit aperture. The edge of the active transmit aperture is rounded by a Tukey window, to reduce side lobes. The resulting transmit aperture and its apodization is seen in Fig. 1a.

In receive, $4 \times 4$ lines must be beamformed within each transmit beam. The beamwidth in receive should therefore be one fourth of the transmit beamwidth, requiring the receive aperture to be four times as wide as the transmit aperture. This gives an 80x80 element large receive aperture, which can not be implemented on the available $32 \times 32$ element transducer. Different aperture layouts have been analyzed in [4], [5]. In this work, the receive aperture is chosen as two crosses with a width of 32 elements and a total of 316 active elements. The receive aperture is shown in Fig. 1b. The focus point is placed at a distance of $50 \mathrm{~mm}$, giving an $\mathrm{F} \#$ of 8.3 .

\section{B. Synthetic aperture imaging}

The SAI system inherits from the Explososcan design the number of active channels and the number of emissions it may use to image one volume.

Where Explososcan uses the same aperture for each emission, SAI slides the active aperture between each emission on the transducer surface. For each emission, SAI synthesizes a virtual source (VS) which is an element in the synthesized aperture.

\footnotetext{
${ }^{1}$ It is here used that $\mathrm{FWHM}=\lambda F \#=\lambda r / w$.
}

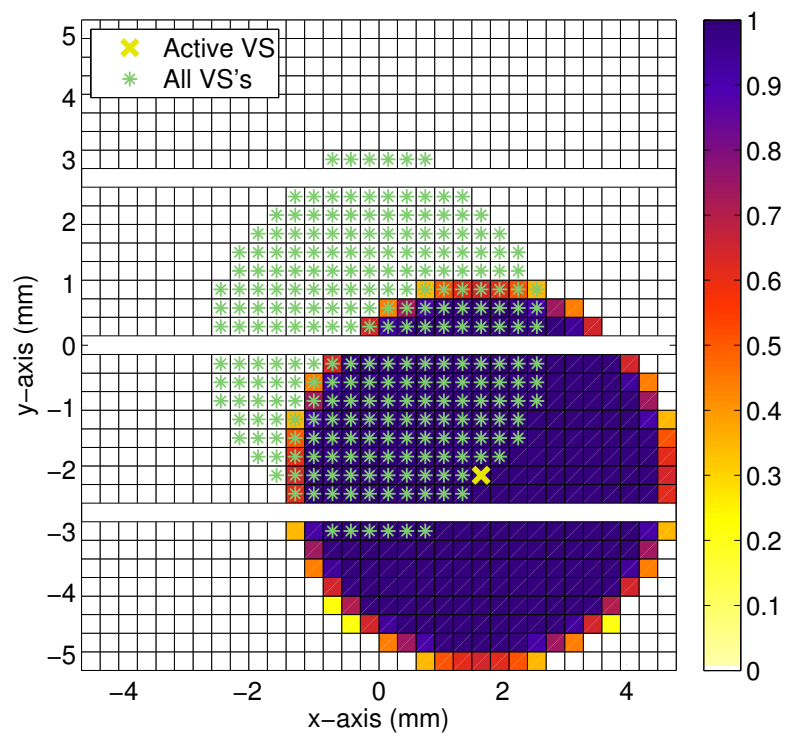

Fig. 2. The apodization of one of SAI's transmit apertures. The virtual source being synthesized in this emission is indicated with a yellow cross The synthesized aperture consists of all the green stars.

The synthesized aperture therefore has 256 elements, ordered as a circle with a diameter of approximately 18 elements. This is illustrated in Fig. 2, where the synthesized virtual source is shown with a yellow cross. By comparing with Exploscan's transmit aperture, which has a diameter of 20 elements, it is seen that SAI's synthesized transmit aperture is slightly smaller. The virtual source is placed at $5 \mathrm{~mm}$ depth, giving an F\# of 0.83 .

\section{MEASUREMENT SETUP}

All measurements are carried out using the 1024 channel experimental scanner synthetic aperture real-time ultrasound system (SARUS). SARUS can acquire data on all 1024 individual channels for a couple of heart beats, and is capable of transmitting any kind of excitation. It samples with $70 \mathrm{MHz}$ in 12 bit. The ultrasound probe used in the measurements is a piezocomposite matrix transducer with 1024 elements, made by Vermon S.A., Tours, France. The probe is composed of four $2 \mathrm{D}$ sub-apertures, that each contains $8 \times 32$ elements. The sub-apertures are joined into one 2D array. On the junction between sub-apertures, there is an inactive row with a width of one pitch. The transducer elements are, thus, organized as $35 \times 32$ elements, and inactive rows are placed at rows 9, 18

TABLE I

TRANSDUCER PARAMETERS

\begin{tabular}{lcc}
\hline \hline Parameter name & Notation & Value \\
\hline Center frequency & $f_{0}$ & $3.5 \mathrm{MHz}$ \\
Transducer pitch $-\mathrm{x}$ & $d_{x}$ & $300 \mu \mathrm{m}$ \\
Transducer pitch $-\mathrm{y}$ & $d_{y}$ & $300 \mu \mathrm{m}$ \\
Active number of elements $-\mathrm{x}$ & $N_{a c t} x$ & 32 \\
Active number of elements $-\mathrm{y}$ & $N_{a c t} y$ & 32 \\
Inactive rows & - & $9,18,27$ \\
\hline \hline
\end{tabular}




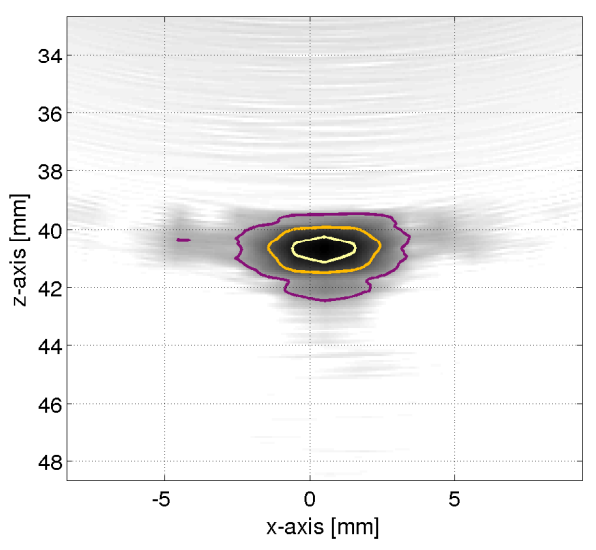

(a) SAI, wire at $40 \mathrm{~mm}$ depth.

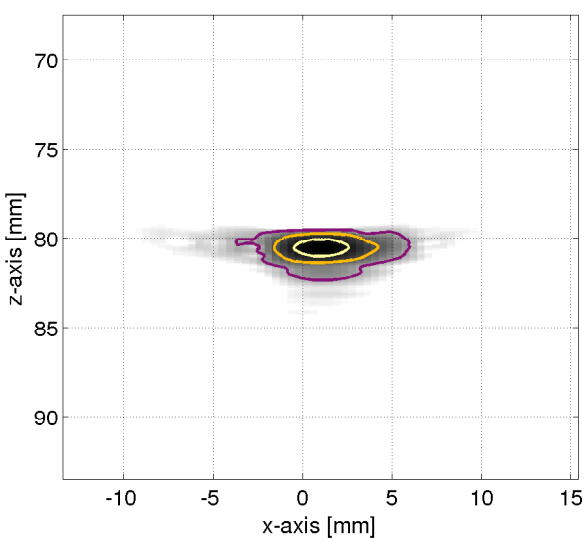

(c) SAI, wire at $80 \mathrm{~mm}$ depth.
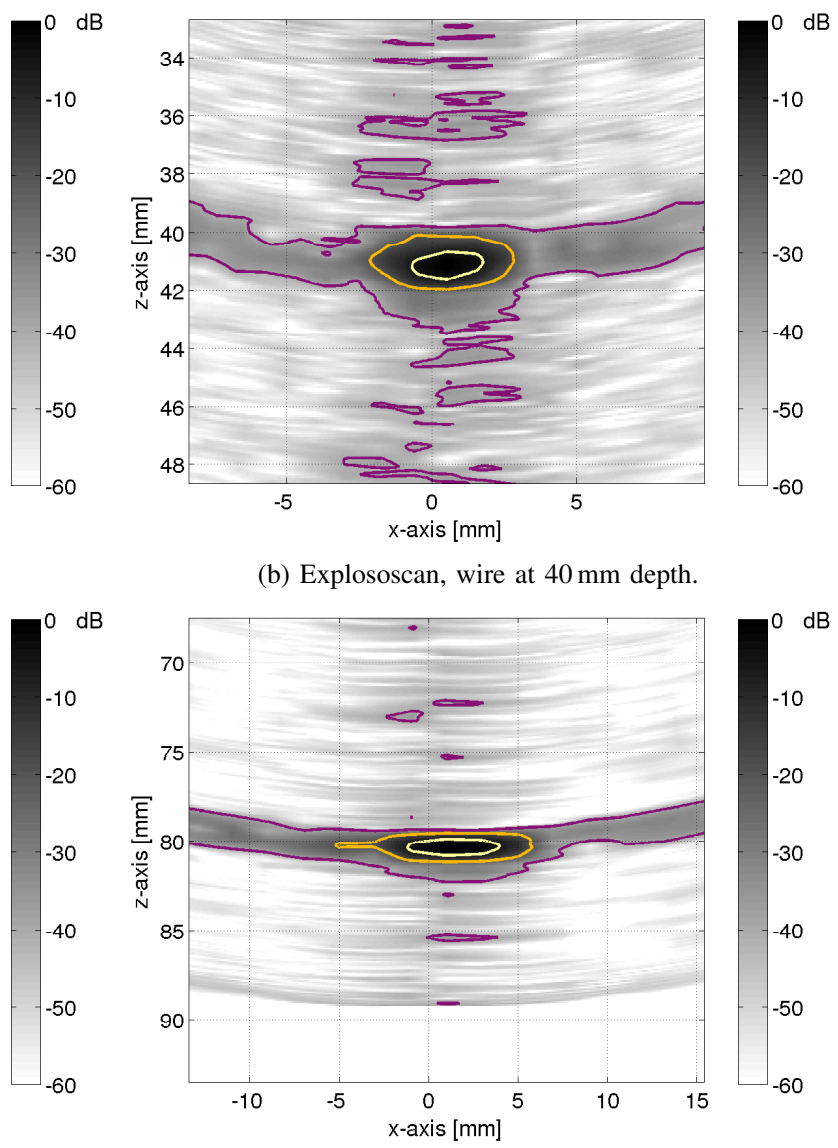

(d) Explososcan, wire at $80 \mathrm{~mm}$ depth.

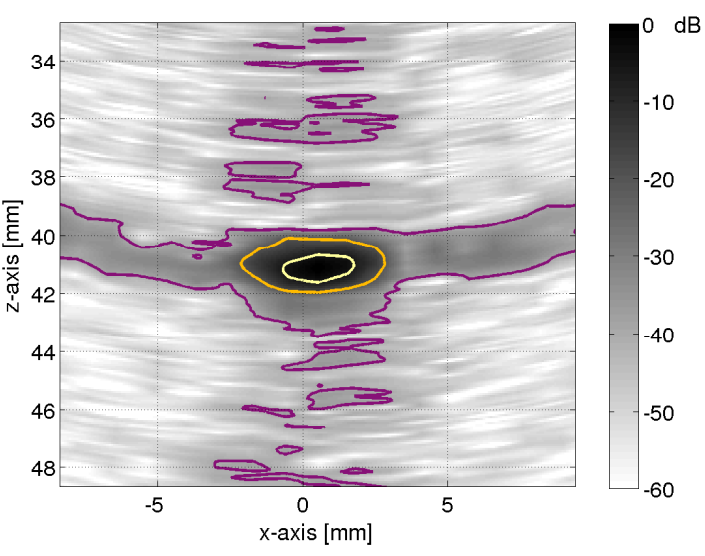

(b) Explososcan, wire at $40 \mathrm{~mm}$ depth.

$\mathrm{I}$ and the right with Explososcan. The $\mathrm{x}$-axis is the same as used in Fig. 1 and 2, and the $\mathrm{z}$-axis is orthogonal to the transducer surface. To ease the comparison, three isocurves at $-6 \mathrm{~dB},-20 \mathrm{~dB}$ and $-40 \mathrm{~dB}$ are overlaid on the PSFs.

and 27. The transducer parameters are listed in Table I, and the inactive elements are shown as white stripes in Fig. 1 and 2.

The wire phantom used consists of thin cobber wires with a diameter of $0.07 \mathrm{~mm}$. The wires are located at $40 \mathrm{~mm}$ and $80 \mathrm{~mm}$ depth. The tissue phantom used is model 571 made by Danish Phantom Service, which mimics the properties of real tissue.

\section{REsults}

When slicing a volume measurement of a wire orthogonal to the wire direction, a 2D slice of the 3D point spread function (PSF) is observed. Fig. 3 shows the measured PSF of both SAI and Explososcan at approximately $40 \mathrm{~mm}$ and $80 \mathrm{~mm}$ depth with a $60 \mathrm{~dB}$ dynamic range. At both depths, the PSF of SAI is seen to have lower side lobes and be more circular symmetric than the PSF of Explososcan. At $40 \mathrm{~mm}$ depth, which is close to Explososcan's focal point, the main lobe size of the two techniques are similar. The FWHM is at $40 \mathrm{~mm}$ depth measured to $2.2 \mathrm{~mm}$ for SA imaging against $2.5 \mathrm{~mm}$ for the Explososcan technique. At $80 \mathrm{~mm}$ depth, which is far away from Explososcan's focal point, the main lobe is $3.4 \mathrm{~mm}$ for SAI and $5.2 \mathrm{~mm}$ for Explososcan. The noise floor is seen to be higher in both of Explososcan's PSFs than for SAI's PFSs. A low peak value at the center of Explososcan's PSF is causing the relative high noise floor. The wire used is very thin and reflects therefore little energy. Explososcan only has a single emission where the main lobe is reflected by the wire. In contrast, in SAI all 256 broad emission beams get reflected by the wire and are coherently summed after the beamforming. The low SNR in the Explososcan measurements are probably the reason for its high side lobe levels.

From the PSFs shown in Fig. 3 the clutter to total energy ratio (CTR) [6], [7] is calculated and shown in Fig. 4. The CTR predicts the contrast between the center of an anechoic cyst embedded in a continuously back scattering media and its surroundings, and is given by:

$$
\operatorname{CTR}(R)=\sqrt{\frac{E_{\text {out }}(R)}{E_{\text {tot }}}},
$$

where $E_{\text {out }}$ is the signal energy outside a circular region with radius, $R$, centered on the peak of the PSF and $E_{t o t}$ is the total PSF energy. This can be used to predict how well an imaging system can detect small cysts. As seen from Fig. 4 


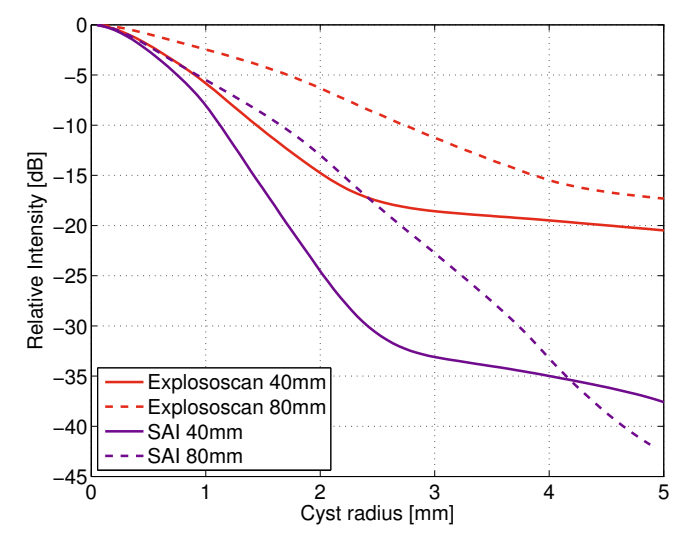

Fig. 4. Clutter to total energy ratio extracted from the PSFs in Fig. 3.

will a small cyst appear darker in a SAI image than in an Explososcan image. The $R_{20 \mathrm{~dB}}$ is how large a cyst has to be to obtain an intensity difference of $20 \mathrm{~dB}$. The smaller the cyst radius, the better. At $40 \mathrm{~mm}$ depth the $R_{20 \mathrm{~dB}}$ is for SAI $1.7 \mathrm{~mm}$ and for Explososcan it is $4.5 \mathrm{~mm}$, and at $80 \mathrm{~mm}$ depth $R_{20 \mathrm{~dB}}$ has increased to $2.8 \mathrm{~mm}$ and $8.3 \mathrm{~mm}$, respectively.

In Fig. 5 two C-scans of the tissue mimicking phantom at a depth of $30 \mathrm{~mm}$ is seen. The spatial variance, or "block artifact", is visible in the Explososcan C-scan in Fig. 5b, whereas it is not visible in the SAI C-scan in Fig. 5a.

\section{DISCUSSION AND CONCLUSION}

3D measurements made with both SAI and with Explososcan was presented. SAI was found to have a smaller main lobe, lower side lobes and better a lower noise floor than Explososcan. At $40 \mathrm{~mm}$ their main lobe sizes were similar, but at $80 \mathrm{~mm}$ depth SAI outperformed Explososcan. SAI was shown to have a better cystic resolution than Explososcan. The speckle pattern was for SAI more pleasant to look at than the boxed speckle pattern of Explososcan.

\section{ACKNOWLEDGMENTS}

This work was financially supported by grant 024-2008-3 from the Danish Advanced Technology Foundation and from BK Medical ApS, Herlev, Denmark.

\section{REFERENCES}

[1] D. P. Shattuck, M. D. Weinshenker, S. W. Smith, and O. T. von Ramm, "Explososcan: A parallel processing technique for high speed ultrasound imaging with linear phased arrays," Journal of the Acoustical Society of America, vol. 75, pp. 1273-1282, 1984.

[2] O. T. von Ramm, S. W. Smith, and H. G. Pavy, "High-speed ultrasound volumetric imaging system - Part II: Parallel processing and image display," IEEE Transactions on Ultrasonics, Ferroelectrics, Control, vol. 38, pp. 109-115, 1991.

[3] M. F. Rasmussen, J. M. Hansen, G. Férin, R. Dufait, and J. A. Jensen, "Preliminary comparison of 3D synthetic aperture imaging with explososcan," in Novel Beamforming Approaches, J. G. Bosch and M. M. Doyley, Eds., vol. 8320. SPIE, 2012, pp. 83 200F 1-9. [Online]. Available: http://link.aip.org/link/?PSI/8320/83200F/1

[4] S. W. Smith, H. G. Pavy, and O. T. von Ramm, "High-speed ultrasound volumetric imaging system - Part I: Transducer design and beam steering," IEEE Transactions on Ultrasonics, Ferroelectrics, Control, vol. 38, pp. 100-108, 1991.

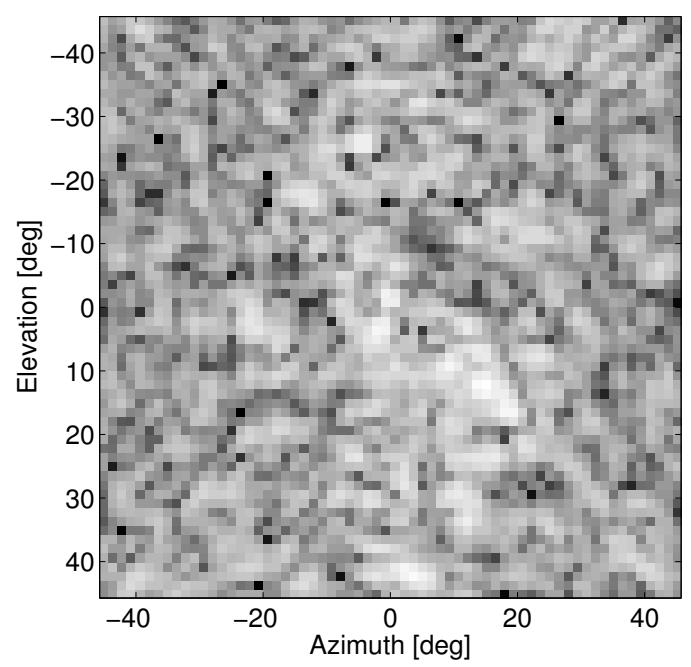

(a) SAI C-scan.

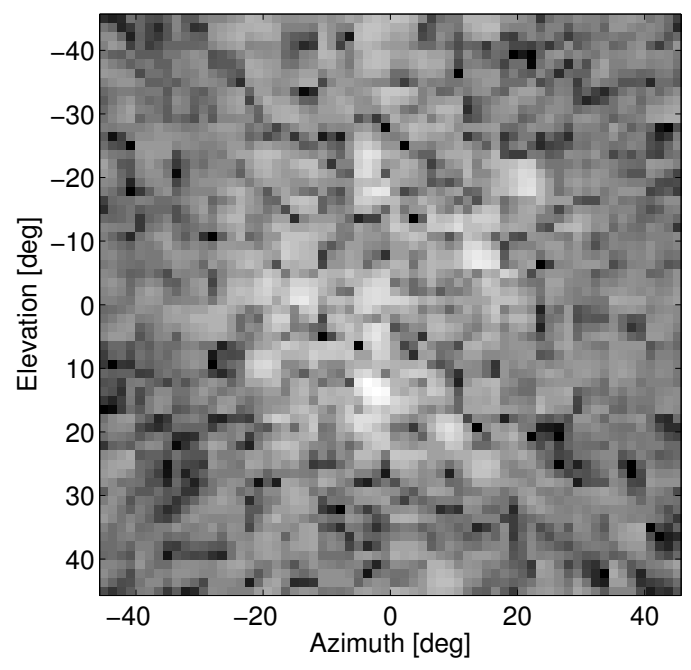

(b) Explososcan C-scan.

Fig. 5. Explososcan and SAI C-scan of speckle in a tissue mimicking phantom. The C-scan is made at a depth of $30 \mathrm{~mm}$ and the dynamic range is $40 \mathrm{~dB}$ Each of the $64 \times 64$ pixels represents one scan line.

[5] M. Karaman, I. Wygant, O. Oralkan, and B. Khuri-Yakub, "Minimally redundant 2-D array designs for 3-D medical ultrasound imaging," Medical Imaging, IEEE Transactions on, vol. 28, no. 7, pp. 1051 -1061, Jul. 2009.

[6] D. Vilkomerson, J. Greenleaf, and V. Dutt, "Towards a resolution metric for medical ultrasonic imaging," in Ultrasonics Symposium, 1995. Proceedings., 1995 IEEE, vol. 2, nov 1995, pp. 1405 -1410 vol.2.

[7] K. Ranganathan and W. Walker, "Cystic resolution: A performance metric for ultrasound imaging systems," Ultrasonics, Ferroelectrics and Frequency Control, IEEE Transactions on, vol. 54, no. 4, pp. 782 -792, april 2007. 